\title{
Investigation of cereal toxicity in coeliac disease*
}

\author{
P.J. Ciclitira and H.J. Ellis
}

Division of Medicine, The Rayne Institute, United Medical School of Guy's and St Thomas' Hospitals, London SE1 7EH, UK.

\begin{abstract}
Summary: Coeliac disease is exacerbated by wheat gluten. A review of methods for the purification, identification and quantitation of wheat proteins to investigate coeliac disease is presented.

Recent developments including amino acid sequencing and expression of wheat protein peptides in $E$. coli should permit characterization of the cereal peptide that exacerbates coeliac disease.
\end{abstract}

\section{Introduction}

Coeliac disease first mentioned by Gallen was described by Samuel Gee in $1888^{1}$ as a wasting disease associated with oatmeal porridge-like stools that affected both children and adults. The pathology of the small intestine was first noted by Paulley ${ }^{2}$ and later described by Shiner \& Doniach. ${ }^{3}$ The principal abnormality is a loss of the normal villous architecture of the small intestine. Early treatment of the condition included Hass's use of the banana diet. ${ }^{4}$ However, it was not until Professor Dicke's observations that it became clear that a cereal-free diet could be used to treat the disorder. ${ }^{5}$ Substances that were found to exacerbate coeliac disease included wheat, rye, barley and possibly oats, ${ }^{5-8}$ although the toxicity of the latter cereal remains in dispute. ${ }^{9}$

In order to characterize the toxic fraction that exacerbates coeliac disease we used wheat as our starting material. Wheat grains can be separated into the outer husk or bran, the germ or semolina and the endosperm or flour (Figure 1) which in the United Kingdom represents $70-72 \%$ of the total grain weight. The main constituents of wheat flour are starch $(70-72 \%)$, protein $(7-15 \%)$, lipids $(1-2 \%)$ and water $(14 \%)$. Osborne $(1907)^{10}$ categorized wheat endosperm proteins into four solubility classes: albumins, which are soluble in water; globulins, which are soluble in salt solutions ( $10 \%$ sodium chloride) but are insoluble in water; gliadins, (wheat prolamins) which are soluble in $50-90 \%$ ethanol and glutenins which are insoluble in neutral aqueous or saline

Correspondence: P.J. Ciclitira, M.D., Ph.D. M.R.C.P.

Received: 14 April 1987

*Based on a lecture given to the European Medical Research Group on 11 December 1986 solutions and ethanol (Figure 2). Recent work has shown that these solubility characteristics are relative, in particular the lower molecular weight glutenins are now known to be soluble in ethanol. The gliadins are further subdivided into subfractions according to their relative mobility on either starch or polyacrylamide gel electrophoresis in aluminium lactate buffer. ${ }^{11-13}$ The subfractions of gliadin are termed alpha, beta, gamma and omega in decreasing order of electrophoretic mobility. Omega gliadins which lack cystine and methionine are occasionally referred to as athins. Whole gliadin is constituted by approximately $30 \%$ alpha, $30 \%$ beta, $30 \%$ gamma and $10 \%$ omega gliadin.

The ethanol-soluble fraction or prolamins of the other cereals are termed secalins from rye, hordeins from barley, avenins from oats and zeins from nontoxic maize.

\section{Initial studies}

The initial studies by the Dutch group involved separation of wheat into fractions.${ }^{14}$ These included (i) gluten, (ii) a water-soluble fraction that contained starch and some water-soluble proteins including gliadins, (iii) glutenins, (iv) gliadins, (v) the crude fibre, (vi) the fat and (vii) the ash resulting from heating the flour to $500^{\circ} \mathrm{C}$. Clinical testing was performed on a 6 year old child who had shown a distinct positive reaction to gluten. Toxicity was assessed by noting the presence of acute abdominal pain, vomiting and slight signs of shock. A severe reaction was observed with the gliadin preparation while the reaction to glutenin was much less. A mild reaction was observed with the 


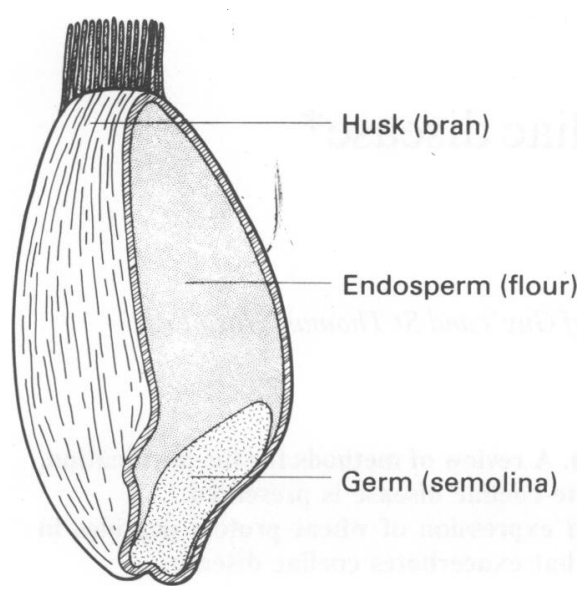

Figure 1 The constituents of a wheat grain.

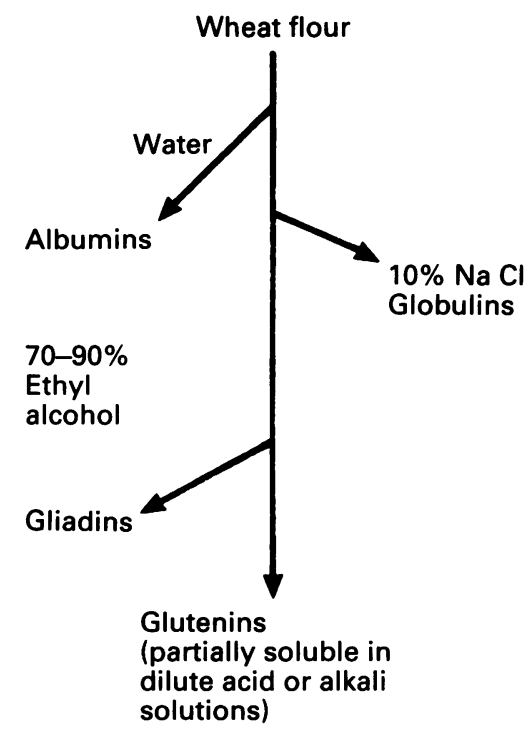

Figure 2 The proteins within wheat flour. water-soluble fraction that contained starch and some gliadin. No reaction was seen with the fat, fibre or ashed fractions. They concluded that the factor in wheat responsible for the exacerbation of coeliac disease was gliadin. ${ }^{14}$

\section{Frazer's fractions}

In order to overcome the poor solubility of wheat क gliadins in buffered solutions, Frazer $e t$ al. produced six peptic-tryptic digests of wheat gluten ${ }^{15}$ (Figure 3). Frazer's fractions I-VI were tested by feeding an amount that would be contained in $10 \mathrm{~g}$ of gluten daily to patients with coeliac disease who were otherwise maintained on a gluten-free diet. A rise in faecal fat was taken as objective evidence of toxicity. All the fractions with the exception of fraction VI were shown to be toxic. The relative toxicity of the fractions could not be assessed because of the small number of patients studied. Fraction III, unlike gluten, glutenins or gliadins, was readily soluble in buffered salt solutions and consequently was adopted as the universal material to investigate coeliac disease.

Dissanayake $e t$ al. fractionated Frazer's fraction III into three further fractions termed A, B and C (Figure 4) and showed that fractions $B$ and $C$ exacerbated coeliac disease while A did not. ${ }^{16}$ Offord et al. subఠ̊ divided fraction B by gel filtration into B1, B2 ane B3. ${ }^{17}$

Frazer's fraction III was found to be a mixture of polypeptides which were similar in chemical and physical properties and therefore difficult to separate. Therefore attention returned to the undigested alpha, beta, gamma and omega gliadin subfractions which could be separated by ion exchange chromatography. Hekkens et al. reported that a sample of alpha gliadin judged to be $80 \%$ pure by starch gel electrophoresis was enterotoxic to a treated coeliac patient by infusing $7.5 \mathrm{~g}$ intraduodenally in a treated coeliac patient and noting histological relapse in serial jejunal biopsies. ${ }^{18}$ Kendall et al. in 1972, separated gliadin into twelve fractions by ion exchange chromatography and pooled them into three groups which they termed prealpha, alpha and post-alpha gliadins. They reported that only the alpha fraction was toxic but failed to provide evidence for the purity of their fractions and used the D-xylose test, an inaccurate method of assessment to investigate their fractions. ${ }^{19}$

\section{Separation and purification of putative toxic fractions}

The definition of wheat protein fractions proposed by Osborne in $1907^{10}$ depends on the relative solubility of the fractions. Despite improved methods of separation and purification, Osborne's classification has not been 
Scheme of enzyme degradation of gluten, and preparation of fractions

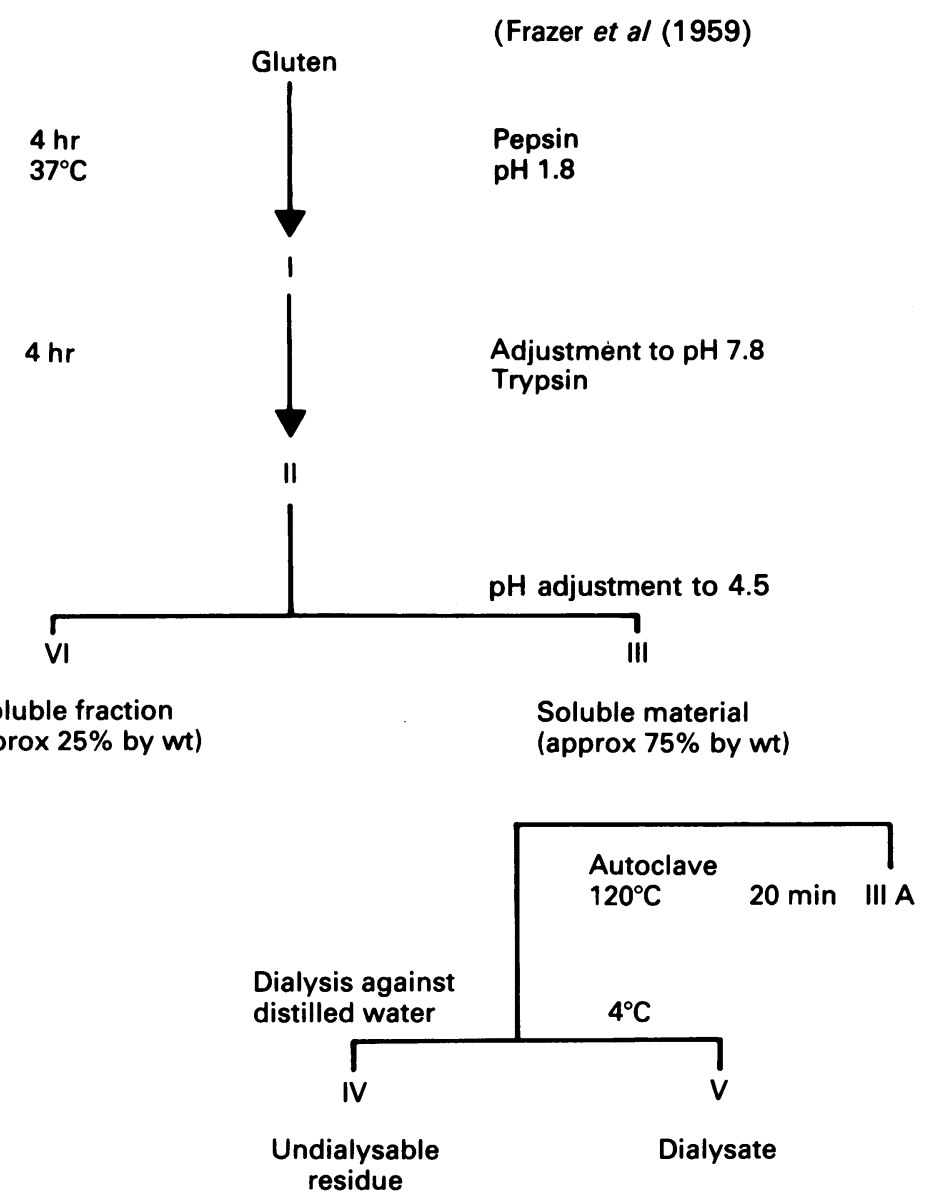

Figure 3 The Frazer fractions of wheat gluten.

superseded, so that not only the purity but also the method of purification and starting material needs to be defined for any given fraction. There is also a lack of primary standards with which to compare fractions, although the baking industry has developed a classification that compares the electrophoretic pattern of gliadins present in different wheat cultivars. For the preparation of wheat protein subfractions, we used specific strains of wheat which were milled to provide white flour.

\section{Wheat gliadins}

Two methods for the purification have been described. ${ }^{20,21}$
Method 1 We used a mixture of Timmo and Waggoner wheat strain white flour which was twice defatted with $n$-butanol. One kg of flour was mixed with 4 litres of $n$-butanol and stirred at room temperature for 2 hours. The $n$-butanol was decanted from the slurry which was placed on a sheet of Whatman $3 \mathrm{M}$ paper and dried in a stream of air. The defatted flour was extracted with $70 \%(\mathrm{v} / \mathrm{v})$ ethanol $(4$ litres) and the supernatant concentrated by rotary evaporation at $30^{\circ} \mathrm{C}$. The concentrated extract was made up to $0.1 \mathrm{M}$ acetic acid and lyophilized (unfractionated gliadin). This unfractionated gliadin was dissolved in an aqueous solution of $1 \mathrm{M}$ dimethylformamide $/ 0.1 \mathrm{M}$ acetic acid/0.005 $\mathrm{M}$ sodium acetate and applied to a Whatman CM52 ion exchange column 
Scheme of Fractionation of Frazer's Fraction III (Dissanayake et al 1974)

Frazer's Fraction III

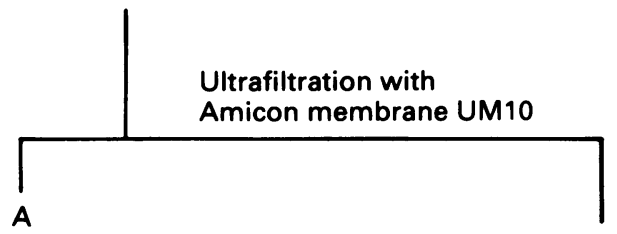

Diffusible fraction
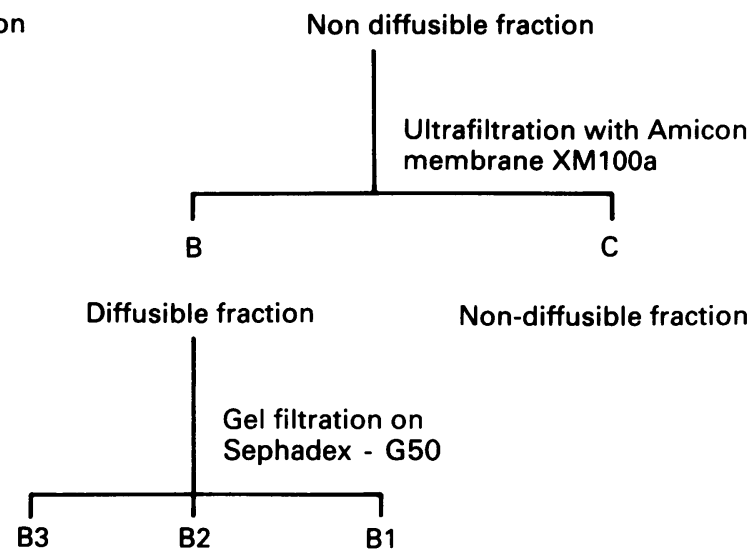

Molecular pore size of Amicon UM10 membrane approximately $1 \times 10^{5}$ Molecular pore size of Amicon XM100a membrane approximately $1 \times 10^{4}$ Fractions $\mathrm{C}, \mathrm{B}$ and $\mathrm{B} 3$ are toxic by feeding trials $100 \mathrm{~g}$ of gluten yielded $15 \mathrm{~g}$ of $\mathrm{B}$ $35 \mathrm{~g}$ of $\mathrm{B}$ yielded $15 \mathrm{~g}$ of $\mathrm{B2}$ and $\mathrm{B} 3$

Figure 4 Gluten fractions as described by Offord et al. ${ }^{16}$.

$(22 \times 10 \mathrm{~cm})$. The alpha, beta, gamma and omega gliadin fractions were eluted with increasing concentrations of sodium chloride dissolved in the same buffer. Optical density peaks $\left(\mathrm{OD}^{276}\right)$ of the eluate were pooled, dialysed against $0.1 \mathrm{M}$ acetic acid and lyophilized. From the unfractionated gliadin applied to the column, the approximate yields of the alpha, beta and gamma gliadin subfractions were $21 \%$, while that of omega gliadin was $2 \%$. This was less than the $30 \%$ of alpha, $30 \%$ of beta, $30 \%$ of gamma and $10 \%$ of omega gliadin in the whole gliadin applied to the column, since only the optical density peaks were pooled and the intervening fractions discarded. This method was found to be consistently reproducible and provided gliadin fractions for subsequent toxicity studies.

Method 2 The second, described by Charbonnier \& Mosse $^{21}$ involves separation of unfractionated gliadin on a Sulfopropyl-Sephadex C-50 ion exchange column with subsequent purification of each of the subfrac- tions by either Sephadex G-100 gel filtration or ion exchange chromatography with Sulfoethyl cellulose.

\section{Wheat albumins and globulins}

Method 1 The method we used, described by Patey (personal communication) involved extraction of a mixture of Timmo and Waggoner flour with distilled water $(500 \mathrm{~g}+500 \mathrm{~g}$ in $4000 \mathrm{ml})$. The mixture was stirred for 2 hours at room temperature and then centrifuged for 20 minutes at $1000 \times g$. The residue was stored at $-20^{\circ} \mathrm{C}$. The supernatant was made up to $10 \%$ dimethylformamide and adjusted to $\mathrm{pH} 3.2$ by the addition of $1 \mathrm{M}$ acetic acid. This mixture was applied to a Whatman CM52 ion exchange column $(22 \times 2 \mathrm{~cm})$. The gliadins were eluted with $200 \mathrm{mM}$ $\mathrm{NaCl}$ in the same solution. The eluate was dialysed against $0.1 \mathrm{M}$ acetic acid for 48 hours ( 3 changes), and lyophilized to yield wheat albumins.

The residue from the initial centrifugation above was lyophilized and ground with a pestle and mortar. 
The resultant powder was stirred for 2 hours at $20^{\circ} \mathrm{C}$ with 4 litres of an aqueous solution of $0.1 \mathrm{M} \mathrm{NaCl}$. This mixture was centrifuged for 20 minutes at $1000 \times g$. The supernatant was dialysed against $0.1 \mathrm{M}$ acetic acid for 48 hours ( 3 changes) and lyophilized to yield wheat globulins.

Method 2 We also prepared an albumin and globulin mixture using Patey \& Evans' method ${ }^{20}$ for preparation of gliadin subfractions, in which the albumins and globulins were eluted from a Whatman CM52 ion exchange column with $200-500 \mathrm{mM} \mathrm{NaCl}$ in $1 \mathrm{M}$ dimethylformamide $/ 0.1 \mathrm{M}$ acetic acid $/ 0.005 \mathrm{M}$ sodium acetate, after the gliadins had been eluted with lower concentrations of $\mathrm{NaCl}$ in the same solution. The eluate was dialysed against $0.1 \mathrm{M}$ acetic acid for $\mathbf{4 8}$ hours ( 3 changes) and lyophilized.

Method 3 The last method for separation of albumins and globulins was to extract wheat flour with $0.1 \mathrm{M}$ acetic acid $(1 \mathrm{~kg} / 1000 \mathrm{ml})$, separate the insoluble material by centrifugation at $2000 \times g$ for 20 minutes at room temperature and decant the supernatant which was lyophilized. This lyophilized material was then redissolved in $0.1 \mathrm{M}$ acetic acid $(100 \mathrm{mg} / 5 \mathrm{ml})$ and applied to an $84 \times 3 \mathrm{~cm}$ column. Serial fractions of $3 \mathrm{ml}$ were collected and optical density at $276 \mathrm{~nm}$ recorded. Three separate peaks were observed of which the last contained wheat albumins and globulins.

The purity of each fraction was assessed by either aluminium lactate starch or SDS polyacrylamide gel electrophoresis. We found that Method 1 provided electrophoretically pure wheat albumins, but a globulin fraction that was grossly contaminated with all the gliadin subfractions. Both Methods 2 and 3 provided reproducible electrophoretically pure fractions of mixtures of wheat albumins and globulins.

\section{Wheat glutenins}

Method 1 Glutenins were purified by the method described by Wasik \& Bushuk. ${ }^{22}$ A mixture of Timmo and Waggoner milled white flour $(100 \mathrm{~g})$ was made into a dough which was exhaustively washed in a stream of distilled water to make a gluten ball and then extracted with $1700 \mathrm{ml}$ of AUC (distilled water $/ 0.1 \mathrm{M}$ acetic $\mathrm{acid} / 3 \mathrm{M}$ urea $/ 0.01 \mathrm{M}$ hexadecyltrimethylammonium bromide; CTAB) at room temperature for 2 hours. This mixture was then centrifuged at $20,000 \mathrm{~g}$ for 30 minutes. The supernatant was aspirated, $150 \mathrm{~g}$ of ammonium sulphate added and the mixture stirred for 2 hours at room temperature. The mixture was then left overnight at $4^{\circ} \mathrm{C}$. The voluminous precipitate (PI) was removed by centrifugation at $4^{\circ} \mathrm{C}$ for 5 minutes at $20,000 \mathrm{~g}$. The supernatant, which contained mostly gliadins and albumins was discarded. The centrifuged precipitate (PI) was washed with $100 \mathrm{ml}$ of $70 \%(\mathrm{v} / \mathrm{v})$ ethanol to remove residual solvent. This was dried at room temperature under vacuum to yield crude glutenin. The precipitate was re-extracted in $1700 \mathrm{ml}$ of AUC and precipitated as before with $150 \mathrm{~g}$ of ammonium sulphate and again separated by centrifugation (PPI). The pelleted material (PPI) was washed in $100 \mathrm{ml}$ of $70 \%(\mathrm{v} / \mathrm{v})$ ethanol three times to remove residual solvent and dried at room temperature under vacuum to yield glutenin. Examination of this fraction by aluminium lactate starch gel electrophoresis showed gross contamination with all the gliadin subfractions.

Method 2 An alternative method for separation of wheat glutenins was to extract wheat flour with $0.1 \mathrm{M}$ acetic acid $(100 \mathrm{~g} / 1000 \mathrm{ml})$. Following separation of insoluble material by centrifugation at $2,000 \mathrm{~g}$ for 30 minutes at room temperature, the supernatant was lyophilized. The lyophilized material was then redissolved in $0.1 \mathrm{M}$ acetic acid and applied to a Sephadex G-100 filtration column $(100 \times 3 \mathrm{~cm})$ when $5 \mathrm{ml}$ fractions were collected. The optical density of the serial fractions was determined at $276 \mathrm{~nm}$, when three distinct peaks were observed, of which the initial peak contained electrophoretically pure glutenin.

\section{Methods for identifying cereal proteins}

\section{Aluminium lactate starch gel electrophoresis}

This technique is commonly used by the baking industry to identify different wheat varieties, ${ }^{12}$ since each cultivar has an individual electrophoretic "fingerprint pattern'. The method involves the separation of unreduced proteins according to their electrical charge and molecular weight. In this system, the heavier glutenins either fail to enter the gel matrix, or run close to the origin, while the alpha, beta, gamma and omega gliadin subfractions run in that order as groups of bands and the lighter albumins and globulins run at the front of the gel.

The pattern obtained by aluminium lactate starch gel electrophoresis of the gliadin subfractions that we used for our in vivo challenge experiments in coeliac patients, compared to a single grain of the Maris Huntsman strain of wheat, a standard control, is shown in Figure 5.

\section{Aluminium lactate polyacrylamide gels}

Recently this technique was developed to provide a similar but not identical classification of gliadin subfractions and cultivars. ${ }^{13}$ This is currently the method of choice for the identification of gliadin 


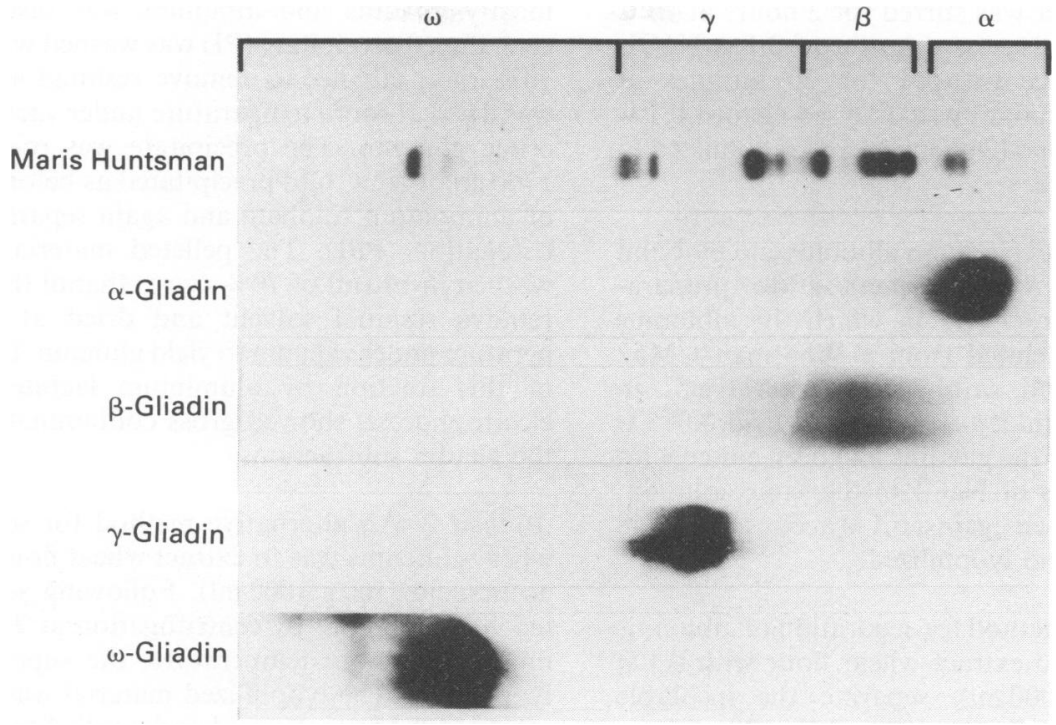

Figure 5 Starch gel electrophoretic pattern of gliadin subfractions used for in vivo challenge studies in coeliac patients, compared to a single grain of the Maris Huntsman strain of wheat.

subfractions, although different techniques outlined below are used for the identification of other wheat protein fractions.

\section{Sodium lauryl sulphate polyacryamide slab electrophoresis (SDS-PAGE)}

Both aluminium lactate starch and polyacrylamide gel electrophoresis involve separation of unreduced proteins. SDS-PAGE involves beta-mercaptoethanol reduction of protein subunits and after the addition of SDS, separation of these subunits according to their relative molecular weight by application of a potential difference across the gel matrix. ${ }^{23}$ In SDS-PAGE, the lighter albumins and globulins mostly run at the front of the gel and the intermediate molecular weight gliadins run in the middle, with some degree of overlap between the alpha, beta, gamma and omega gliadin subfractions. The heavier glutenins, which are largely broken down into subunits, run behind the gliadins, although there is some degree of overlap. The SDSPAGE character of the fractions used for our in vivo challenge studies is shown in Figure 6.

\section{Two dimensional gel electrophoresis}

The protein sample is first separated using isoelectric focussing. This is achieved by use of a polyacrylamide tube gel which contains amberlite exchange resins. The tube gel is then placed on an SDS-PAGE and the proteins separated according to their relative molecular weights, providing a two dimensiona separation. This approach may prove valuable in the production of fractions of greater purity than has hitherto been possible, and may act as a prelude to the characterization of physical structures, serological reactions and amino acid sequences of cereal protein fractions.

\section{Immunoassays}

Recently immunoassays involving both radioimmunoassay and ELISA have been used to investigate the serological relationship of cereal proteins and develop assays for their detection in foods including glutenfree products based on wheat starch that have been found to contain trace amounts of gliadin ${ }^{24-28}$ and to produce symptoms in some treated coeliac patients. ${ }^{29}$ The gliadin proteins, with the partial exception of omega gliadins, have been shown to behave antigenically similarly by Ouchterlony double diffusion, radioimmunoassay binding studies, radioimmunoassay cross-reactivity, and Western immunoblotting with monoclonal antibodies to these proteins. ${ }^{30}$

\section{Assessment of toxicity of cereal fractions}

In vitro organ culture and in vivo challenge studies have been used to assess the toxicity of cereal fractions to 


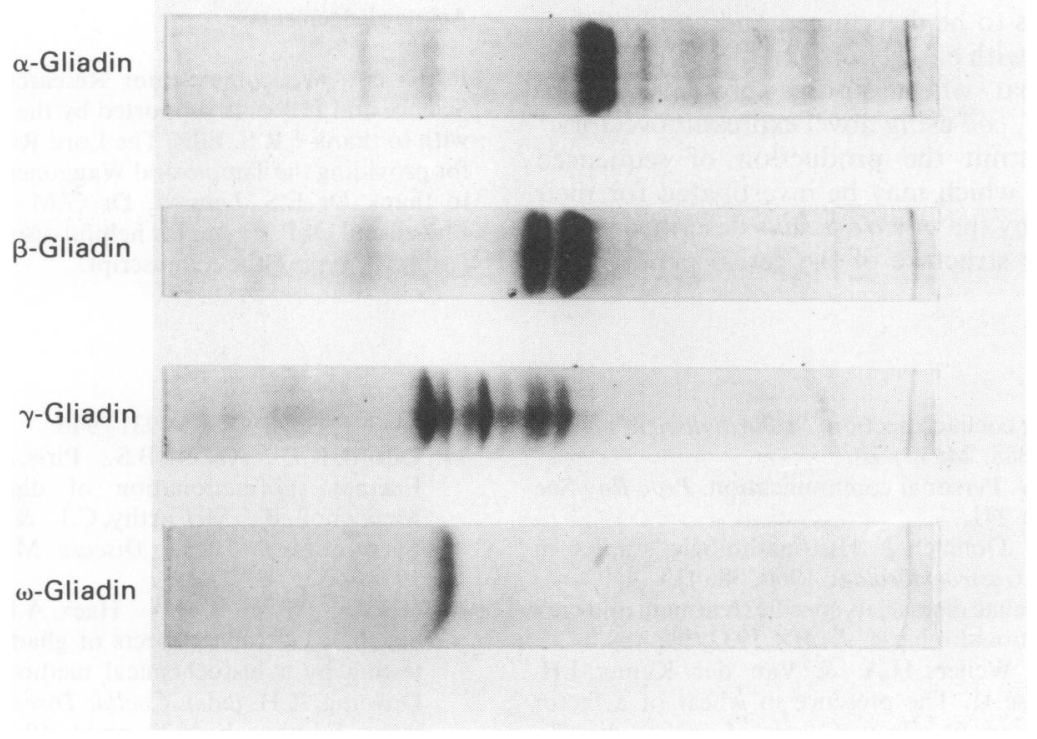

Figure 6 SDS-PAGE pattern of gliadin subfractions used for in vivo challenge studies.

coeliac small intestinal mucosa. Howdle et $_{\text {al }}{ }^{31}$ and Jos et al..$^{32}$ used an in vitro jejunal biopsy culture assay and independently concluded that not only alpha, but beta, gamma and omega fractions of wheat gliadin exacerbate coeliac disease. Kumar et al. reported that only alpha gliadin exacerbates coeliac disease, but did not provide details of their in vivo challenge studies. ${ }^{33}$ We undertook challenge studies in two treated coeliac patients by infusion on different days of $1 \mathrm{~g}$ quantities of alpha, beta, gamma and omega gliadin subfractions. We assessed toxicity by comparing the morphology of jejunal biopsies taken with a Quinton multiple jejunal biopsy capsule prior to and 6 hours after commencing each infusion. We concluded from the results of double blind morphometric assessment of jejunal biopsies before and after the challenges that all four subfractions of wheat gliadin exacerbate coeliac disease in vivo. ${ }^{34}$

\section{Conclusion}

The wheat cereal fraction that exacerbates coeliac disease must be contained within the protein moiety since defatted alpha gliadin that contains less than 0.007 moles of carbohydrate per mole of protein ${ }^{35}$ is known to exacerbate the condition. The close serological relationship of the gliadin proteins as demonstrated by the cross-reactivities of rabbit antisera and monoclonal antibodies, to all four gliadin subfractions $\mathrm{s}^{25,30,36}$ implies that they share epitopes.

The similar N-terminal amino acid sequences present in wheat, rye and barley prolamin $\mathrm{s}^{37-39}$ suggest that a specific amino acid sequence may constitute the toxic determinant. Detoxification of wheat gluten proteins by deamidation ${ }^{40}$ implies that glutamine, which constitutes more than $35 \%$ of the amino acids within gliadin, may be involved. Kagnoff reported that a protein within A-gliadin shares eight amino acids in a residue of twelve amino acids and an identical pentapeptide with the $54 \mathrm{KD}$ protein of human adenovirus $12,{ }^{41}$ an adenovirus usually isolated from the intestinal tract. They suggested that infection with this virus produced a hypersensitivity to the specific peptide which developed into coeliac disease in susceptible subjects. This is a novel approach to the investigation 
of this condition and deserves further study.

cDNA clones coding for wheat storage proteins have been made which permit the amino acid sequence of these proteins to be determined and confirm their close homology with barley hordeins. ${ }^{42}$ Recently, it has been shown that wheat storage proteins can be synthesized in $E$. coli using novel expression vectors. ${ }^{43}$ This should permit the production of sequenced gliadin proteins which may be investigated for their coeliac toxicity by the in vitro assays described above and provide the structure of the cereal peptide that

\section{References}

1. Gee, S. On the coeliac affection. St Bartholomew's Hospital Journal 1888, 24: 17-20.

2. Paulley, J.E.W. Personal communication. Proc Roy Soc Med 1949, 42: 241.

3. Shiner, M. \& Doniach, I. Histopathologic studies in steatorrhoea. Gastroenterology 1960, 38: 419-440.

4. Hass, S.V. Coeliac disease, its specific treatment and cure without nutritional relapse. JAMA 1932, 99: 488.

5. Dicke, W.K., Weijers, H.A. \& Van der Kamer, J.H. Coeliac disease II. The presence in wheat of a factor having a deleterious effect in cases of coeliac disease. Acta Paediatr Scand 1953, 42: 34-42.

6. Rubin, C.F., Brandborg, L.L., Flick, A.L. et al. Biopsy studies on the pathogenesis of coeliac sprue. In Wolsterholme, G.E.W. \& Cameron, M.P. (eds) Intestinal Biopsy. CIBA Foundation study group, 1962, 14: 67-83.

7. Anand, B.S., Piris, J. \& Truelove, S.C. The role of various cereal in coeliac disease. $Q J$ Med 1978, 185: 101110.

8. Baker, P.G. \& Read, A.E. Oats and barley toxicity in coeliac disease. Postgrad Med J 1976, 52: 264-268.

9. Dissanayake, A.S., Truelove, S.C. \& Whitehead, R. Lack of harmful effect of oats on small intestinal mucosa in coeliac disease. $\mathrm{Br}$ Med J 1974, i: 189-191.

10. Osborne, T.B. The proteins of the wheat kernel. Carnegie Inst., Washington, Washington DC, 1907.

11. Woychik, H.H., Boundy, J.A. \& Dimiter, R.J. Starch gel electrophoresis of wheat gluten proteins with concentrated urea. Arch Biochem Biophys 1961, 94: 477-482.

12. Ellis, J.R.S. Behminster, C.H. The identification of UK wheat varieties by starch gel electrophoresis of gliadin proteins. J Natn Inst Agric Bot 1977, 14: 221-231.

13. Bushuk, W. \& Zillman, R.R. Wheat cultures identification by gliadin electropherograms. I Apparatus, method and nomenclature. Can J Plant Sci 1978, 58: 505-515.

14. Van der Kamer, J.H., Weijers, H.A. \& Dicke, W.K. Coeliac disease iv. An investigation into the injurious constituents of wheat in connection with their action on patients with coeliac disease. Acta Paediatr Scand 1953, 43: 223-231.

15. Frazer, A.C., Fletcher, R.G., Ross, C.A.C., Shaw, B., Sammons, H.C. \& Schneider, R. Gluten-induced enteropathy. The effect of partially digested gluten. Lancet 1959, ii: 252-255.

16. Dissanayake, A.S., Jerrome, D.W., Offord, R.E., Truelove, S.C. \& Whitehad, R. Identifying toxic fractions of wheat gluten and their effect on the jejunal mucosa in coeliac exacerbates coeliac disease.

\section{Acknowledgements}

P.J.C. is a Wellcome Senior Research Fellow in Clinical Science and H.J.E. is supported by the Wellcome Trust. We with to thank J.R.S. Ellis, The Lord Rank Research Centre, for providing the Timmo and Waggoner wheat. We also wish to thank Dr E.S. Lennox, Dr G.M. Murphy and Dr R. Flavell and Dr P. Frazer for helpful discussions and Mrs B.E. Issom for typing the manuscript.

disease. Gut 1974, 15: 931-946.

17. Offord, R.E., Anand, B.S., Piris, J. \& Truelove, S.C. Further subfractionation of digests of gluten. In McNicholl, B., McCarthy, C.I. \& Fottrell, P.F. (eds) Perspectives in Coeliac Disease. MTP Press, Lancaster, 1978, pp 25-32.

18. Hekkens, W. Th. J.M., Haex, A.D.C.L. \& Willihagen, R.G. Some aspects of gliadin fractionation and testing by a histochemical method. In Booth, C.C. \& Dowling, R.H. (eds). Coeliac Disease. Churchill Livingstone, Edinburgh, 1970, pp 11-19.

19. Kendall, M.H., Schneider, R., Cox, P.S. \& Hawkins, C.F. Gluten subfractions in coeliac disease. Lancet 1972, ii: 1065-1967.

20. Patey, A.L. \& Evans, D.J. Large scale preparation of gliadin proteins. J Sci Fd Agric 1973, 24: 1229-1293.

21. Charbonnier, L. \& Mosse, J. Large scale isolation of gliadin fractions. J Sci Fd Agri 1980, 31: 54-61.

22. Wasik, R.H. \& Bushuk, W. Alternative methods for separation of glutenins. Cereal Chemistry 1974, 51: 112118.

23. Weber, K. \& Osborne, M. The reliability of molecular weight determinations by dodecyl-sulphate polyacrylamide gel electrophoresis. J Biol Chem 1969, 15: 4406-4412.

24. Windemann, H., Fritschy, F. \& Baumgartner, F. Enzyme-linked immunosorbent assay for wheat alpha gliadin and whole gliadin. Bioch Biophys Acta 1982, 709: 110-121.

25. Ciclitira, P.J., Ellis, H.J., Evans, D.J. \& Lennox, E.S. Relationship of antigenic structure of cereal proteins to their toxicity in coeliac patients. Br J Nutr 1985, 53: 3945.

26. Ciclitira, P.J., Ellis, H.J., Evans, D.J. \& Lennox, E.S. A radioimmunoassay for wheat gliadin to assess the suitability of gluten-free products with coeliac disease. Clin Exp Immunol 1985, 59: 703-708.

27. Freedman, A.R., Galfre, G., Gal, E., Ellis, H.J. \& Ciclitira, P.J. Monoclonal antibody ELISA to quantitate wheat gliadin contamination of gluten-free foods. $J$ Immunol Methods 1987, In press.

28. Freedman, A.R., Galfre, G., Gal, E., Ellis, H.J. \& Ciclitira, P.J. Detection of wheat gliadin contamination of gluten-free foods by a monoclonal antibody dot immunobinding assay. Clin Chim Acta 1987, In press.

29. Ciclitira, P.J., Cerio, R., Ellis, H.J., Maxton, D., Nelufer, J.M. \& Macartney, J.M. Evaluation of a gliadin containing gluten-free product in coeliac patients. Hum 
Nutr Clin Nutr 1985, 39c: 303-308.

30. Ellis, H.J., Gal, E., Freedman, A.R. \& Ciclitira, P.J. Western immunoblotting of cereal peptides with a monoclonal antibody to wheat gliadin to investigate coeliac disease. Clin Sci 1987, 72, Suppl 16: 31P.

31. Howdle, P.D., Ciclitira, P.J., Simpson, F.O. \& Loswosky, M.S. Are all gliadins toxic in coeliac disease? An in vitro study of alpha, beta, gamma and omega gliadins. Scand J Gastroenterol 1984, 19: 41-47.

32. Jos, J. The toxic fraction of gliadin digests in coeliac disease. Isolation by chromatography on Biogel P-10. Clin Chim Acta, 119: 263-274.

33. Kumar, P.J., Sinclair, T.S., Farthing, M.J.G. et al. Clinical toxicity testing of pure gliadin in coeliac disease. Gastroenterology 1984, 86: Abstract 1147.

34. Ciclitira, P.J., Evans, D.J., Lennox, F.S., Fagg, N.L.K. \& Dowling, R.H. Clinical testing of gliadin fractions in coeliac patients. Clin Sci 1984, 66: 357-364.

35. Bernardin, J.E., Saunders, R.H.M. \& Kasarda, D.D. Absence of carbohydrate in coeliac-toxic A-gliadin. Cereal Chem 1976, 53: 612-614.

36. Skerritt, J.H., Smith, R.A., Wrigley, C.W. \& Underwood, P.A. Monoclonal antibodies to gliadin proteins used to examine cereal grain homologies. Cereal Science 1984, 12: 215-224.
37. Bietz, J.A., Huebner, F.R., Sanderson, J.E. \& Walls, J.S. Wheat gliadin homology revealed through N-terminal amino acid sequence analysis. Cereal Chem 1977, 54: 1070-1083.

38. Autran, J.C., Lew, E.J.L., Nimmo, C.C. \& Kasarda,D.D. N-terminal amino acid sequencing of prolamins from wheat and related species Nature 1979, 282: $527-529$.

39. Shewry, P.R., Autran, J.C., Nimmo, C.C., Ellen, J., Law, L. \& Kasarda, D.D. N-terminal amino acid sequence homology of storage protein components from barley and a diploid wheat. Nature 1980, 286: 520-522.

40. Van de Kamer, J.H. \& Weijers, H. Coeliac disease. Some experiments on the cause of the harmful effect of wheat gliadin. Acta Paediatr Scand 1955, 144: 465-469.

41. Kagnoff, M.F., Raleigh, K.A., Hubert, J.J., Bernardin, J.F. \& Kasarda, D.D. Possible role of a human adenovirus in the pathogenesis of coeliac disease. $J$ Exp Med 1981, 160: 1544-1547.

42. Bartels, B. \& Thompson, R.D. The characterization of cDNA clones coding for wheat storage proteins. Nucleic Acids Res 1983, 11: 2961-2977.

43. Bartels, D., Thompson, R.D. \& Rothstein, S. Synthesis of a wheat storage protein subunit in $E$. coli using novel expression vectors. Gene 1985, 35: 159-167. 